\title{
A Case Report of Migrating Fish Bone to the Thyroid Gland
}

\author{
Mouhannad Abdulber Fakoury ${ }^{a}$ Hasan Said Abdulbaki ${ }^{b}$ Eyad Darraj ${ }^{c}$ \\ Fateh Almohammad Alsalem ${ }^{\mathrm{a}}$ \\ ${ }^{a}$ ENT Department, Dubai Hospital, Dubai Health Authority, Dubai, UAE; ${ }^{\text {b }}$ Department of Otorhinolaryngology, \\ Primary Health Care Corporation, Doha, Qatar; ' King's Mill Hospital, Sutton-in-Ashfield, UK
}

\section{Keywords}

Emergency · ENT · Fish bone · Foreign body · Thyroid gland . Gastroenterology · General surgery · Otolaryngology

\begin{abstract}
Fish bone as a foreign body in the throat is common and frequently seen in emergency departments. In most cases, the bone is stuck in the tonsils or oropharynx, some go further to the laryngopharynx, and in rare cases they may go furthest. The authors report a rare case of a fish bone that migrated to the thyroid gland.

(C) 2020 The Author(s)

Published by S. Karger AG, Basel
\end{abstract}

\section{Introduction}

Fish bones as swallowed foreign bodies can be managed by direct removal using headlight or require an endoscopic approach. Some even need open surgery. Some bones may penetrate the mucosa of the upper aerodigestive tract and migrate to neck soft tissues and organs. In such cases, patient complaints are of unusual presentation for swallowed foreign bodies, and patients may suffer different complications that require a more aggressive management

\begin{tabular}{ll}
\hline karger@karger.com & ( ) 2020 The Author(s) Karger \\
www.karger.com/dmj & Published by S. Karger AG, Basel Open access \\
& This article is licensed under the Creative Commons Attribution- \\
Karger & NonCommercial-NoDerivatives 4.0 International License (CC BY- \\
NC-ND) (http://www.karger.com/Services/OpenAccessLicense). \\
Usage and distribution for commercial purposes as well as any dis- \\
tribution of modified material requires written permission.
\end{tabular}

\section{Case Presentation}

A 49-year-old female presented to the emergency room with a 15-day history of mild throat pain, developed while eating fish, followed by mild dysphagia and neck pain not associated with cough, drooling, or voice change.

The patient had a medical history of hypothyroidism and was on regular follow-up at the endocrine clinic. She also had controlled hypertension on amlodipine. ENT examination and flexible laryngoscopy were normal, except for a mild swelling of the lower right neck associated with mild pain and tenderness.

\section{Investigations}

Plain X-ray of neck soft tissues showed a linear shadow in the neck that was identified as a foreign body, most likely a fish bone.

Ultrasound of the neck showed a linear echogenic shadow with surrounding fluid collection with a thick wall and surrounding hyperemia posterior to the right thyroid lobe, the right side of the trachea, and medial to the carotid sheath. The aggregation measured roughly $2.5 \times 2 \mathrm{~cm}$ and was inseparable from the posterior face of the right thyroid lobe. The described picture was suggestive of a thyroid abscess around a foreign body (fish bone), and no suspected esophageal perforation was seen. For better assessment, contrast-enhanced CT scan was performed.

Computer tomography scan of the neck showed a linear, radiodense foreign body measuring $25 \mathrm{~mm}$ in length and $2 \mathrm{~mm}$ in thickness and located in the right parapharyngeal and paratracheal region. The proximal end was noted in the posterolateral wall of the hypopharynx on the right side at the level of the lower end of the thyroid cartilage, suggesting the site of penetration. The distal end was within the right lobe of the thyroid (Fig. 1-3). Most of the fish bone was situated in the right lobe of the thyroid gland, and

Mouhannad Abdulber Fakoury 


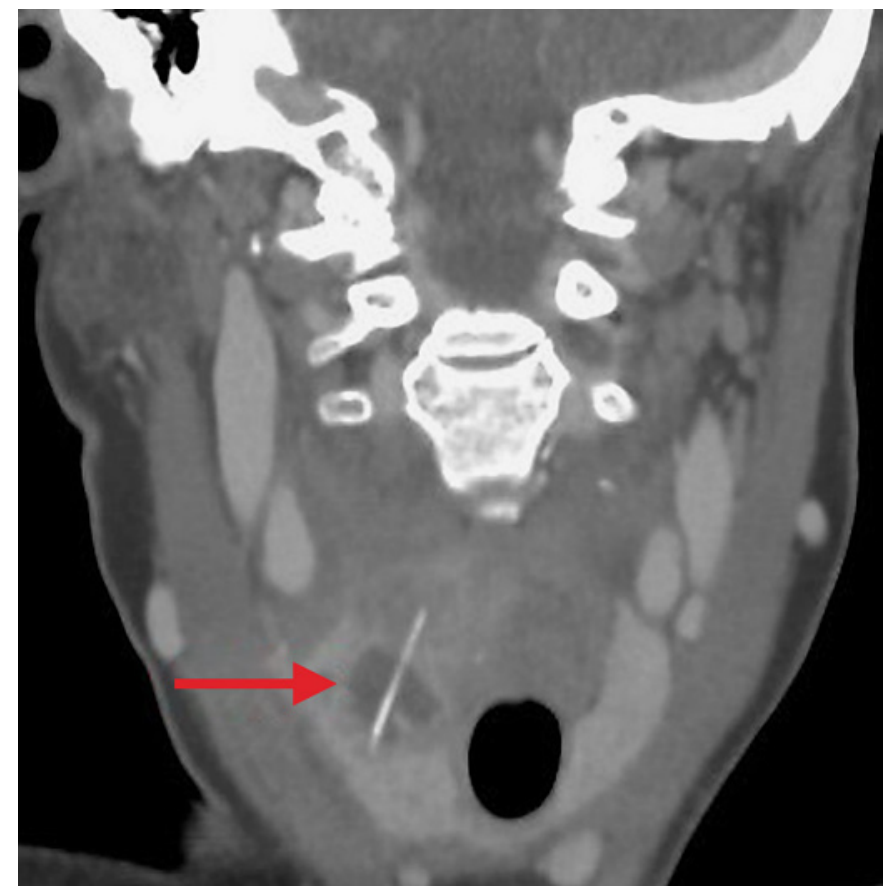

Fig. 1. CT of the coronal section showing a fish bone and fluid collection in the thyroid gland.

there were fluid collections in the thyroid measuring $2.4 \times 2.5 \times 2.3$ $\mathrm{cm}$. Soft tissue enhancement and swelling was seen proximal to the right thyroid lobe, extending cranially up to the superior cornu. Strap muscles on the right side showed swelling. The soft tissue swelling with enhancement was seen in the retropharyngeal areas, and minimal fluid collection was detected in the retropharyngeal space extending upwards to the level of the sinus piriformis.

There was strong suspicion of inflammation with abscess formation, as described above.

\section{Case Follow-Up}

The patient was referred to the general surgery department where the endocrinology and gastrointestinal teams were consulted.

The endocrinologist reported a controlled case of hypothyroidism, taking thyroxine $50 \mu \mathrm{g}$ once daily for the last 6 years, and no contraindication for surgery. Gastrointestinal consultant review mentioned that the foreign body was located deeply in the soft tissue and out of our field, so we advised on removal by the general surgery team. General surgery review advised incision and drainage of the thyroid abscess and removal of the foreign body \pm right hemithyroidectomy \pm total thyroidectomy.

\section{Surgical Management}

The patient underwent surgical procedure for exploration and removal of the foreign body under general anesthesia in the supine position. Preoperatively, the thyroid was found to be hard rocklike with inflammatory changes.

\section{Procedure}

The neck was extended, prepared, and draped in standard fashion. A transverse cervical incision was made $2 \mathrm{~cm}$ above the sternal

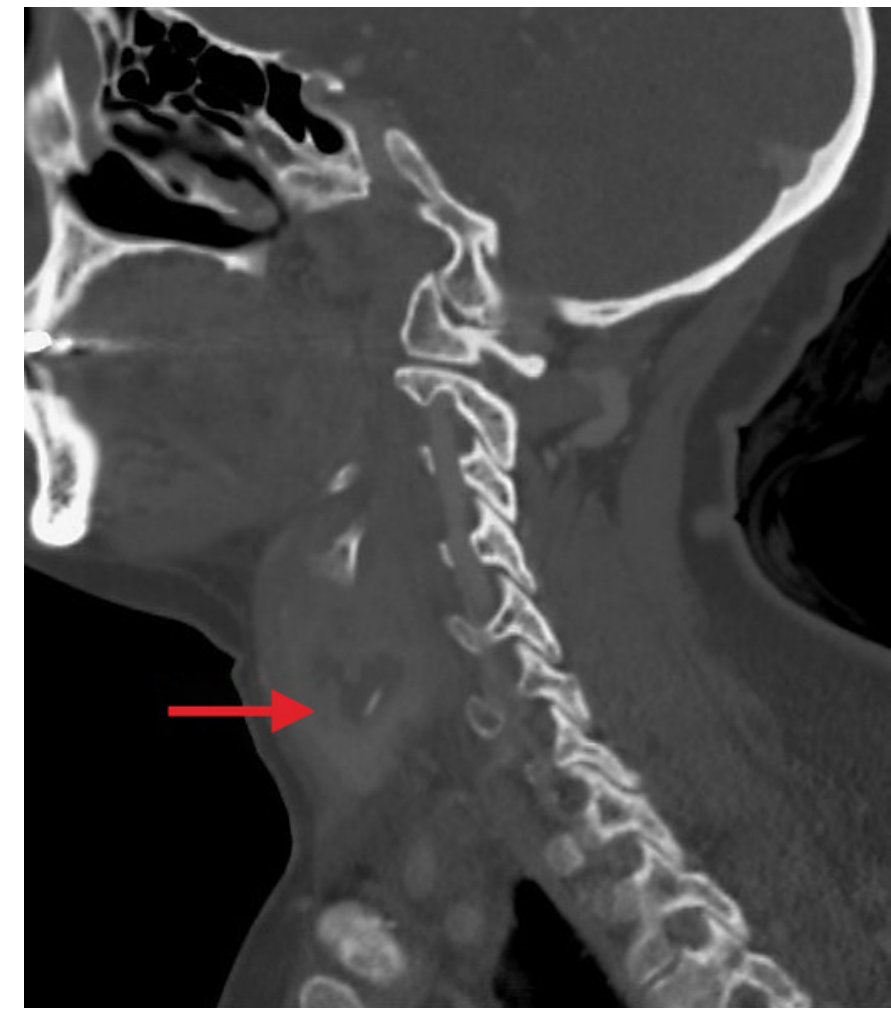

Fig. 2. CT of the sagittal section showing a fluid collection in the thyroid and a fish bone.

notch along a natural skin fold. The strap muscles were identified and divided at the midline. Blunt dissection was used to mobilize the right thyroid lobe in a medial direction. Dissection continued posteriorly and superiorly, and the superior pedicle was ligated. A small cavity $1 \times 1 \mathrm{~cm}$ with the foreign body (fish bone) was seen, and the foreign body was removed. The strap muscles were closed with an interrupted 2-0 Vicryl suture. The platysma was closed with an interrupted 2-0 Vicryl suture, followed by subcutaneous continuous layer, which was also closed with an interrupted 2-0 Vicryl suture, and the skin incision was closed with a 4-0 Monocryl subcuticular closure. Steri-Strips were applied across the incision. Dry dressing was applied and pressured. After surgery, the patient showed complete recovery without complications.

\section{Discussion}

Pharyngoesophageal and laryngotracheal foreign bodies can range widely in their presentation. Diagnosis is usually based on three diagnostic tools: clinical history, physical examination, and imaging [1]. Radiography plays a central role in diagnosis. Delay in diagnosis may lead to greater complications.

Fish bones as foreign bodies are common, usually easily located and removed. However, sometimes they be- 


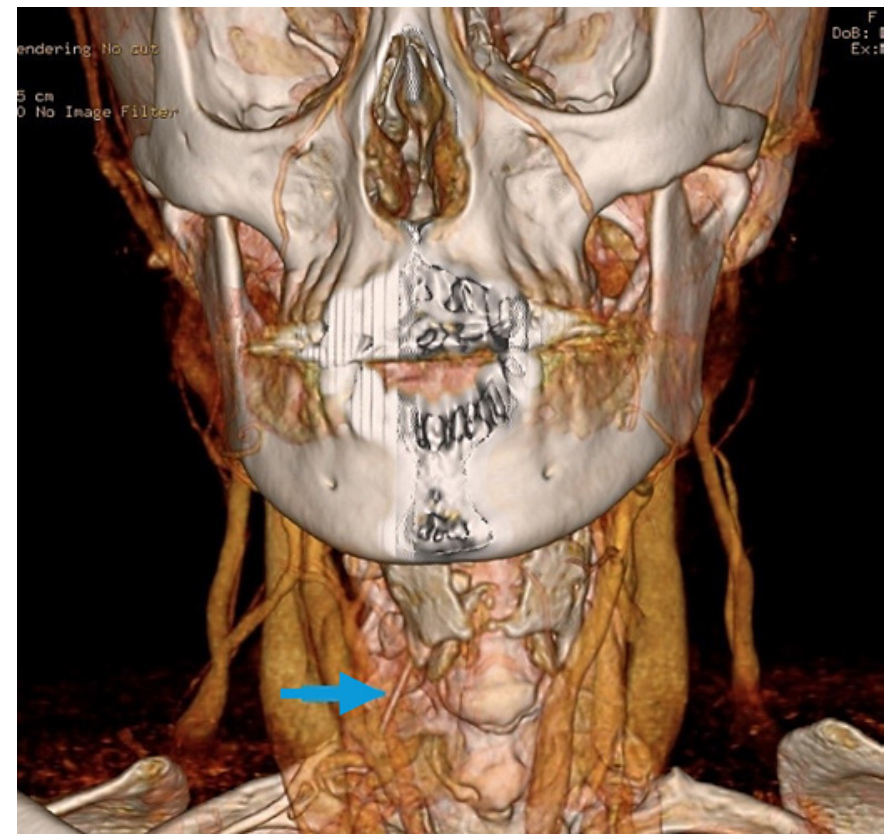

Fig. 3. CT $3 \mathrm{D}$ reconstruction.

come embedded in the pharyngeal wall and neck soft tissue and cannot be located [2] even by fiberoptic endoscopy or rigid esophagoscopy. Left in place, the foreign bodies can cause serious complications. A small percentage of fish bones may penetrate the alimentary tube wall and will be found either intra- or extraluminally [3]. Migration of esophageal foreign bodies to the thyroid gland and presentation as a mass are extremely rare. However, in a reported case the fish bone penetrated through the esophagus and migrated to the right upper lobe of the lung [4]. The case presented with recurrent pneumonia and was misdiagnosed for 5 years. Finally, the patient was submitted to a right upper lobectomy and a fish bone was found in the lung parenchyma.
One publication in the literature [5] mentioned 6 cases of fish bones that caused perforation of the duodenum, small intestine, and ileum with injuries to the mesenteric vessels, resulting in massive bleeding in the cecum and colon. All patients were operated and 2 patients died.

Another case of thyroid abscess was reported [6] in a 50 -year-old female who had fever and a painful mass in the anterior neck. An intrathyroidal abscess was diagnosed, and a foreign body that proved to be a fish bone was removed.

\section{Conclusion}

Fish bones are potential causes of unpredictable complications when swallowed as foreign bodies. They bear the risk of damaging the mucosa along the alimentary tract tube and migrating far, causing abscesses, recurrent infections, or acute profuse bleeding.

\section{Statement of Ethics}

The patient approved the publication of this case report.

\section{Conflict of Interest Statement}

The authors have no conflicts of interest to disclose.

\section{Funding Sources}

The authors did not receive any funding.

\section{Author Contributions}

M.A.F.: designed and wrote the manuscript. H.S.A.: performed the literature review. E.D.: reviewed the manuscript. F.A.A.: collected the data and reviewed the manuscript.

\section{References}

1 Digoy GP. Diagnosis and management of upper aerodigestive tract foreign bodies. Otolaryngol Clin North Am. 2008 Jun;41(3):485-96.

2 Shu MT, Leu YS. Microscopic removal of an embedded foreign body from the hypopharynx: report of two cases. Ear Nose Throat J. 2001 Dec;80(12):889-90.
3 Bendet E, Horowitz Z, Heyman Z, Faibel M, Kronenberg J. Migration of fishbone following penetration of the cervical esophagus presenting as a thyroid mass. Auris Nasus Larynx. 1992;19(3):193-7.

4 Pan S, Chai Y, Shen G. Recurrent pneumonia caused by a migrated esophageal foreign body. Thorac Cardiovasc Surg. 2013 Sep; 61(6):513-5.
5 Legchilo AN. [Perforations of the gastrointestinal tract by a fish bone]. Vestn Khir Im I Grek. 1979 Apr;122(4):64-6.

6 Chen CY, Peng JP. Esophageal fish bone migration induced thyroid abscess: case report and review of the literature. Am J Otolaryngol. 2011 May-Jun;32(3):253-5. 